\title{
Risk Factors for Nephrotoxicity Associated with Cisplatin
}

\author{
Karine Almanric, Nathalie Marceau, Ariane Cantin, and Émilie Bertin
}

\begin{abstract}
Background: Cisplatin-induced nephrotoxicity occurs in about one-third of patients who receive this chemotherapy drug. In late 2012, the study institution began measuring serum creatinine on day 7 after administration of cisplatin to identify patients with acute renal failure.

Objective: To evaluate the extent of nephrotoxicity associated with cisplatin and the influence of risk factors for nephrotoxicity.

Methods: This retrospective study involved patients who received a first cycle of cisplatin-based chemotherapy between November 1, 2012, and November 1, 2013. Patients' medical records were reviewed to determine the increase in creatinine level (graded according to the National Cancer Institute Common Terminology Criteria for Adverse Events) and the influence of certain prespecified risk factors, such as age, concomitant medications, initial dose of cisplatin, and related medical conditions.

Results: Among the 80 patients evaluated, 14 (17\%) experienced no increase in the level of serum creatinine (grade 0), 44 (55\%) experienced a grade 1 increase, $19(24 \%)$ a grade 2 increase, and $3(4 \%)$ a grade 3 increase; no patients experienced a grade 4 increase. Patients with the greatest risk of a grade 2 or 3 increase were those treated with hydrochlorothiazide (odds ratio [OR] 9.35, 95\% confidence interval [CI] 2.49 to 35.14$)$ or an angiotensin-converting enzyme inhibitor or angiotensin II receptor blocker (OR 5.02, 95\% CI 1.76 to 14.32). After adjustment, only hydrochlorothiazide was associated with an increased risk of nephrotoxicity (OR 5.39, 95\% CI 1.04 to 28.07). Among patients taking hydrochlorothiazide, the average incremental increase in serum creatinine was $59.9 \mu \mathrm{mol} / \mathrm{L}$ ( $95 \%$ CI 34.3 to $85.4 \mu \mathrm{mol} / \mathrm{L}$ ).
\end{abstract}

Conclusions: Taking hydrochlorothiazide was associated with a significant increase in serum creatinine following cisplatin therapy. On the basis of these results, patients should stop taking hydrochlorothiazide before undergoing cisplatin-based chemotherapy.

Keywords: cisplatin, nephrotoxicity, renal failure, hydrochlorothiazide, angiotensin-converting enzyme inhibitor, nonsteroidal anti-inflammatory drug

\section{Can J Hosp Pharm. 2017;70(2):99-106}

\section{RÉSUMÉ}

Contexte : La néphrotoxicité associée au cisplatine se produit chez environ le tiers des patients qui reçoivent ce médicament de chimiothérapie. À la fin de 2012, l'établissement de santé des auteurs a commencé à mesurer la créatinine sérique au jour 7 après l'administration de cisplatine afin de repérer les patients atteints d'insuffisance rénale aiguë.

Objectif : Évaluer le degré de la néphrotoxicité associée au cisplatine et déterminer si des facteurs de risque favorisent cette néphrotoxicité.

Méthodes : Cette étude rétrospective a été menée auprès de patients ayant subi un premier cycle de chimiothérapie à base de cisplatine entre le premier novembre 2012 et le premier novembre 2013. Les dossiers médicaux des patients ont été examinés afin de détecter les cas d'augmentation de créatinine sérique (qui ont été classés selon les critères pour une terminologie commune des événements indésirables du National Cancer Institute) et l'influence de facteurs de risque préétablis (âge, médicaments concomitants, dose initiale de cisplatine et pathologies associées).

Résultats : Parmi les 80 patients analysés, 14 (17\%) n’affichaient aucune augmentation du taux de créatinine sérique (degré 0), 44 (55\%) présentaient une augmentation de degré 1, 19 (24\%) affichaient une augmentation de degré 2 et $3(4 \%)$ présentaient une augmentation de degré 3; aucun ne présentait une augmentation de degré 4 . Les patients qui couraient le plus grand risque de connaître une augmentation de degré 2 ou 3 étaient ceux traités avec l'hydrochlorothiazide (risque relatif approché [RRA] de 9,35, intervalle de confiance [IC] à $95 \%$ de 2,49 à 35,14) ou d'un inhibiteur de l'enzyme de conversion de l'angiotensine ou d'un bloqueur des récepteurs de l'angiotensine II (RRA de 5,02, IC à $95 \%$ de 1,76 à 14,32). Après ajustement, seul l'hydrochlorothiazide était associé à une augmentation du risque de néphrotoxicité (RRA de 5,39, IC à $95 \%$ de 1,04 à 28,07). Parmi les patients qui prenaient de l'hydrochlorothiazide, l'augmentation différentielle moyenne de créatinine sérique était de 59,9 $\mu \mathrm{mol} / \mathrm{L}$ (IC à $95 \%$ de 34,3 à 85,4 $\mu \mathrm{mol} / \mathrm{L})$.

Conclusions : La prise concomitante d'hydrochlorothiazide a été associée à une augmentation significative de la créatinine sérique après un traitement de cisplatine. Considérant ces résultats, les patients devraient cesser de prendre de l'hydrochlorothiazide avant de recevoir une chimiothérapie à base de cisplatine.

Mots clés : cisplatine, néphrotoxicité, insuffisance rénale, hydrochloro -thiazide, inhibiteur de l'enzyme de conversion de l'angiotensine, antiinflammatoire non stéroïdien 


\section{INTRODUCTION}

Pisplatin-induced nephrotoxicity occurs in about one-third of patients who receive this type of chemotherapy. Generally, nephrotoxicity occurs within 10 days after cisplatin is administered, and it is evidenced by a reduction in glomerular function, an increase in serum creatinine, and lower levels of magnesium and potassium. ${ }^{1}$

The prevalence of cisplatin-induced nephrotoxicity varies between $5 \%$ and $45 \%$, depending on the study and the definitions used. ${ }^{2,3}$ It is lower when the chemotherapy is combined with hydration. ${ }^{4,5}$ The mechanism explaining cisplatin-induced nephrotoxicity is complex. Exposing tubular cells to cisplatin activates signalling pathways that cause injury to the proximal and distal tubular cells, as well as to the collecting tubules. Inflammation also ensues, exacerbating renal tissue damage. Tubular toxicity may also lead to cell death by necrosis or apoptosis. Cisplatin may also cause damage to the renal vessels, resulting in an ischemic injury to the kidneys and reducing glomerular filtration. These effects culminate in the loss of kidney function, leading to acute renal failure. ${ }^{1}$

In 2008, the European Society of Clinical Pharmacy (ESCP) published recommendations for preventing cisplatin-induced nephrotoxicity, ${ }^{5,6}$ such as estimating renal function through the Modification of Diet in Renal Disease method or according to the Cockcroft-Galt equation and adjusting the dose of cisplatin accordingly; maintaining euvolemia in patients before, during, and after treatment; administering the cisplatin slowly; ensuring daily diuresis of 3-4 L on the day before the treatment and for 2 or 3 days after the treatment; avoiding diuretics, including furosemide and mannitol; doing follow-up testing of serum creatinine 3-5 days after the cisplatin is administered; controlling the serum concentration of magnesium and providing supplementation if necessary; and avoiding the concomitant administration of nephrotoxic agents (e.g., aminoglycosides, nonsteroidal antiinflammatory drugs [NSAIDs], contrast media). ${ }^{5}$

At the authors' centre, several of the ESCP recommendations are being applied. Renal function is calculated before each cisplatin cycle, and the dose is adjusted accordingly. Cisplatin is administered slowly, at a maximum rate of $1 \mathrm{mg} / \mathrm{min}$ or less. All patients receive forced hydration of $0.9 \%$ sodium chloride and $20 \mathrm{mEq} / \mathrm{L}$ potassium chloride on the day that cisplatin is administered, for a total of 2-3 L. Patients are also encouraged to drink 2-2.5 L/day for 2 or 3 days after chemotherapy. However, diuresis is not measured routinely. Electrolytes are monitored and supplied (if required) at each cycle of cisplatin. Starting November 1, 2012, serum creatinine has been measured on day 7 after administration of cisplatin. This measure identifies patients with acute renal failure, which previously went unnoticed in some cases. The institution's internal procedure is to intervene systematically for grade 2 or 3 increases of creatinine (see below for information about grading).
This retrospective study was conducted to evaluate the increase in serum creatinine one week after administration of a first cycle of cisplatin-based chemotherapy; to list the interventions performed; and to analyze the influence of certain risk factors, such as concomitant medication.

\section{METHODS}

\section{Study Design}

This retrospective cohort study was conducted at the Centre intégré de cancérologie de Laval, Quebec, an oncology outpatient clinic treating an average of 200 patients per week. The study was carried out between November 1, 2012, and November 1, 2013, and the duration of follow-up for each patient was about 21 to 28 days, the duration of one cycle of chemotherapy. The primary objective was to evaluate the change in the level of serum creatinine after a first cycle of cisplatin-based chemotherapy. The secondary objectives were to list the interventions performed for patients who experienced an increase in serum creatinine on day 7 and to evaluate the risk factors for cisplatin-induced nephrotoxicity, such as concomitant nephrotoxic medications (hydrochlorothiazide, angiotensin-converting enzyme $[\mathrm{ACE}]$ inhibitors, angiotensin II receptor blockers [ARBs], NSAIDs) or the presence of certain related medical conditions (hypertension, nausea or dehydration, diarrhea, limited fluid intake, past exposure to cisplatin, arteriosclerotic heart disease, myocardial infarction, bypass, type 2 diabetes mellitus). The study was conducted under the authorization of the institution's director of professional services and the ethics review board.

\section{Population and Treatment}

All patients who received a first cycle of cisplatin-based chemotherapy at the oncology outpatient clinic between November 1, 2012, and November 1, 2013, were included in the study. The following chemotherapy protocols were represented: cisplatingemcitabine, ${ }^{7}$ for stage 4 non-small-cell lung cancer; cisplatinvinorelbine (BR-10), ${ }^{8}$ for localized non-small-cell lung cancer; cisplatin-vinblastine (RTOG-9410), ${ }^{9}$ for stage 3 non-smallcell lung cancer; and epirubicin-cisplatin-5-fluorouracil, ${ }^{10}$ for stage 4 stomach or esophageal cancer. Patients who were beyond their first cycle of chemotherapy were excluded. Patients were identified by the centre's MOSAIQ software (Elekta AB, Stockholm, Sweden). MOSAIQ is an electronic medical system specific to oncology, which allows for the complete multidisciplinary management of chemotherapy, from prescription to administration.

The following patient characteristics were documented: age, sex, smoking status, and performance status (Eastern Cooperative Oncology Group [ECOG]; http://ecog-acrin.org/resources/ ecog-performance-status). The use of imaging with a contrast agent between days 1 and 7 after cisplatin administration was also verified. Serum creatinine values preceding the first dose of cisplatin and on day 7 of the first cycle of chemotherapy (with 
day 1 defined as the date of chemotherapy administration) were recorded. Any increase in the level of serum creatinine was graded according to the standardized criteria of the National Cancer Institute Common Terminology Criteria for Adverse Events (NCI-CTCAE), version 4.03. ${ }^{11}$ The NCI-CTCAE toxicity scale defines a grade 1 increase in serum creatinine as $1-1.5$ times the baseline value or up to 1.5 times the upper limit of normal; grade 2 as 1.5-3.0 times the baseline value or upper limit of normal; grade 3 as more than 3 times the baseline value or 3-6 times the upper limit of normal; and grade 4 as a creatinine value more than 6 times the upper limit of normal. We defined grade 0 toxicity as serum creatinine equal to or less than the baseline value.

For all patients, interventions (hydration, taking an electrolyte supplement, changing or stopping chemotherapy, reducing the dose of cisplatin, delaying treatment, or discontinuing a medication [ACE inhibitor, ARB, NSAID]) were documented from the hemato-oncologist's and the pharmacist's notes.

We searched for the following potentially confounding variables: medications (hydrochlorothiazide, ACE inhibitor, ARB, NSAID) and related medical conditions (hypertension, nausea or dehydration, diarrhea, limited fluid intake, past exposure to cisplatin, arteriosclerotic heart disease, myocardial infarction, bypass, type 2 diabetes). These data were taken from the hematooncologist's and pharmacist's notes. For example, at the first cycle of chemotherapy, the pharmacist systematically documented patients' medication history in their files. We also looked for other medications that could alter renal function. Age and dose of cisplatin were also considered potentially confounding variables.

\section{Analyses}

SPSS Statistics for Windows software, version 19.0 (IBM, Armonk, New York), was used to conduct the statistical analyses. Descriptive statistics were used to describe the population studied. Differences in proportions were calculated with the Pearson, Fisher, and Monte Carlo $\chi^{2}$ tests, and differences in average values were calculated with the Student $t$-test. Odds ratios (ORs) with 95\% confidence intervals (CIs) were calculated. To obtain adequate statistical power, patients who experienced a grade 0 or 1 increase in creatinine were combined, as were those who experienced a grade 2 or 3 increase. A multivariate logistic regression model was used to evaluate the relation between the grade of increase (grades 0 and 1 combined, grades 2 and 3 combined) and certain variables (cisplatin dose, age, related medical condition, and concomitant medications [hydrochlorothiazide, ACE inhibitor, ARB, NSAID]). Finally, a linear regression model was used to evaluate the increase in serum creatinine according to the above-mentioned variables.

\section{RESULTS}

Between November 1, 2012, and November 1, 2013, a total of 80 patients received cisplatin during a first cycle of chemotherapy as part of the protocols specified above. All of these patients were included in the analysis of the results. The average age was 66 years, and $24(30 \%)$ of the patients were smokers when the analysis was conducted (Table 1). Most patients were being treated for lung cancer and had ECOG performance status of 1 . The most common dose of cisplatin was $80 \mathrm{mg} / \mathrm{m}^{2}$. Hydrochlorothiazide was taken by 13 patients (16\%), an ACE inhibitor or ARB by 29 patients (36\%), and an NSAID by 14 patients (17\%). Forty patients $(50 \%)$ had at least one medical condition possibly associated with increased risk of nephrotoxicity (hypertension, diarrhea, limited fluid intake, past exposure to cisplatin, arteriosclerotic heart disease, myocardial infarction, bypass, or type 2 diabetes). Only 2 patients had been exposed to cisplatin during treatment of a prior illness; neither of these patients had abovenormal serum creatinine at baseline, and both had a grade 1 increase in creatinine after cisplatin administration. One patient received IV furosemide on the day of the treatment, and another took this drug regularly; neither of these patients experienced a significant rise in serum creatinine after cisplatin administration (grade 0). Imaging (computed tomography) with contrast agent between days 1 and 7 was used for 6 patients; 5 of these patients experienced a grade 0 or grade 1 increase in serum creatinine, and the other patient experienced a grade 2 increase. None of these patients was taking hydrochlorothiazide.

Of the 80 patients included in the study, $44(55 \%)$ experienced a grade 1 increase in serum creatinine, 19 (24\%) experienced a grade 2 increase, 3 (4\%) experienced a grade 3 increase, and none experienced a grade 4 increase. Fourteen patients (17\%) experienced no increase in creatinine following their chemotherapy. The average increase in serum creatinine was $12 \mu \mathrm{mol} / \mathrm{L}$ among patients who experienced grade 0 or 1 increase in creatinine and $75 \mu \mathrm{mol} / \mathrm{L}$ among those who experienced grade 2 or 3 increase in creatinine (Table 2). The creatinine value returned to baseline in $10(45 \%)$ of the 22 patients who experienced grade 2 or 3 increase in creatinine and $46(79 \%)$ of the 58 patients who experienced grade 0 or 1 increase. None of the patients with a grade 3 increase had their creatinine value return to baseline before starting the second cycle of chemotherapy (between 21 and 28 days after start of first cycle). An intervention was performed for all patients who experienced a grade 2 or 3 increase. Chemotherapy was changed or stopped for 7 (16\%) of patients who experienced a grade 1 increase in creatinine and for $16(73 \%)$ of patients who experienced a grade 2 or 3 increase. None of the patients included in this study required dialysis or admission to hospital for management of increased creatinine.

In terms of potential risk factors for nephrotoxicity, univariate analysis showed that a grade 2 or 3 increase in creatinine was more likely to occur in patients taking hydrochlorothiazide (OR 9.35, 95\% CI 2.49 to 35.14) or an ACE inhibitor or ARB (OR 5.02, 95\% CI 1.76 to 14.32) (Table 3). Using an NSAID, however, did not influence renal function in a statistically significant way. On the basis of logistic multivariate regression, only hydrochlorothiazide 
Table 1. Patient Characteristics

\begin{tabular}{|c|c|c|c|c|}
\hline \multirow[b]{2}{*}{ Characteristic } & \multicolumn{4}{|c|}{$\begin{array}{l}\text { Grade of SCr Increase; } \\
\text { No. (\%) of Patients* }\end{array}$} \\
\hline & \multicolumn{2}{|c|}{ Grade 0 or 1} & \multicolumn{2}{|c|}{ Grade 2 or 3} \\
\hline No. of patients & \multicolumn{2}{|c|}{58} & \multicolumn{2}{|c|}{22} \\
\hline \multicolumn{5}{|l|}{ Age } \\
\hline Mean and SD (years) & 66 & $(45-85)$ & 66 & $(51-79)$ \\
\hline No. $(\%) \geq 65$ years & 36 & $(62)$ & 11 & $(50)$ \\
\hline Sex, male & 28 & $(48)$ & 8 & (36) \\
\hline SCr before first treatment ( $\mu \mathrm{mol} / \mathrm{L})$ (mean) & \multicolumn{2}{|c|}{70} & \multicolumn{2}{|c|}{66} \\
\hline Smoker & 17 & (29) & 7 & (32) \\
\hline \multicolumn{5}{|l|}{ Performance status (Eastern Cooperative Oncology Group) } \\
\hline 0 & 13 & $(22)$ & 6 & $(27)$ \\
\hline 1 & 25 & (43) & 8 & (36) \\
\hline 2 & 2 & (3) & 2 & (9) \\
\hline 3 & 1 & $(2)$ & 0 & (0) \\
\hline NA & 17 & (29) & 6 & $(27)$ \\
\hline \multicolumn{5}{|l|}{ Dose of cisplatin $\left(\mathrm{mg} / \mathrm{m}^{2}\right)$} \\
\hline 100 & 8 & $(14)$ & 5 & $(23)$ \\
\hline 80 & 38 & (65) & 14 & (64) \\
\hline$<80$ & 12 & $(21)$ & 3 & (14) \\
\hline \multicolumn{5}{|l|}{ Cancer type and chemotherapy } \\
\hline $\begin{array}{l}\text { Stage } 4 \text { non-small-cell lung cancer, treated } \\
\text { with cisplatin-gemcitabine }\end{array}$ & 43 & $(74)$ & 15 & (68) \\
\hline $\begin{array}{l}\text { Localized non-small-cell lung cancer, } \\
\text { treated with cisplatin-vinorelbine (BR-10) }\end{array}$ & 6 & $(10)$ & 1 & (5) \\
\hline $\begin{array}{l}\text { Stage } 3 \text { non-small-cell lung cancer, } \\
\text { treated with cisplatin-vinblastine (RTOG-9410) }\end{array}$ & 8 & (14) & 5 & $(23)$ \\
\hline $\begin{array}{l}\text { Stage } 4 \text { stomach cancer, treated with } \\
\text { epirubicin-cisplatin-5-fluorouracil }\end{array}$ & 1 & $(2)$ & 1 & (5) \\
\hline \multicolumn{5}{|l|}{ Concomitant medications } \\
\hline With HCTZ & 4 & $(7)$ & 9 & $(41)$ \\
\hline Without HCTZ & 54 & (93) & 13 & (59) \\
\hline With ACE inhibitor or ARB & 15 & (26) & 14 & $(64)$ \\
\hline Without ACE inhibitor or ARB & 43 & (74) & 8 & (36) \\
\hline With NSAID & 9 & (16) & 5 & (23) \\
\hline Without NSAID & 49 & (84) & 17 & (77) \\
\hline \multicolumn{5}{|l|}{$\begin{array}{l}\text { No. of medical conditions possibly associated with } \\
\text { increased risk of nephrotoxicityt }\end{array}$} \\
\hline None & 33 & $(57)$ & 7 & $(32)$ \\
\hline$\geq 1$ & 25 & (43) & 15 & (68) \\
\hline Imaging with contrast agent between days 1 and 7 & 5 & (9) & 1 & (5) \\
\hline \multicolumn{5}{|c|}{$\begin{array}{l}\text { ACE = angiotensin-converting enzyme, ARB = angiotensin II receptor blocker, } \\
\text { HCTZ = hydrochlorothiazide, NA = not applicable, } \\
\text { NSAID = nonsteroidal anti-inflammatory drug, SCr = serum creatinine, SD = standard deviation. } \\
\text { ^Except where indicated otherwise. Note: Within a given characteristic, percentages may not } \\
\text { sum to exactly } 100 \text { because of rounding. } \\
\text { tMedical conditions possibly associated with an increased risk of nephrotoxicity included } \\
\text { hypertension, diarrhea, limited fluid intake, past exposure to cisplatin, arteriosclerotic heart } \\
\text { disease, myocardial infarction, bypass, and type } 2 \text { diabetes mellitus. }\end{array}$} \\
\hline
\end{tabular}

was associated with a significant increase in creatinine (OR 5.39, 95\% CI 1.04 to 28.07). The dose of cisplatin, the patient's age, and related medical conditions had no statistically significant impact on cisplatin-induced nephrotoxicity.

The level of serum creatinine was also analyzed in relation to the potential risk factors for nephrotoxicity. Linear regression showed increases in serum creatinine of $59.9 \mu \mathrm{mol} / \mathrm{L}$ (95\% CI 34.3 to $85.4 \mu \mathrm{mol} / \mathrm{L}$ ) among patients taking hydrochlorothiazide and $21.4 \mu \mathrm{mol} / \mathrm{L}(95 \% \mathrm{CI} 0.2$ to $42.7 \mu \mathrm{mol} / \mathrm{L})$ among patients using an NSAID (Table 4). Taking an ACE inhibitor or ARB also resulted in an increase in serum creatinine (by $12.1 \mu \mathrm{mol} / \mathrm{L}, 95 \%$ CI -15.0 to 39.2), but this increase was statistically nonsignificant. Age had a statistically significant impact, with each additional year increasing the serum creatinine by $1.1 \mu \mathrm{mol} / \mathrm{L}$ (95\% CI 0.1 to $2.1 \mu \mathrm{mol} / \mathrm{L}$ ). The cisplatin dose and related medical conditions were not shown to increase serum creatinine. 
This single copy is for your personal, non-commercial use only.

For permission to reprint multiple copies or to order presentation-ready copies for distribution, contact CJHP at cjhpedit@cshp.ca

Table 2. Interventions Following Grade 0 to 3 Increase in Serum Creatinine $(n=80)$

\begin{tabular}{|c|c|c|c|c|}
\hline \multirow[b]{2}{*}{ Intervention or Outcome } & \multicolumn{4}{|c|}{ Grade of Increase; No. (\%) of Patients* } \\
\hline & Grade 0 & Grade 1 & Grade 2 & Grade 3 \\
\hline No. of patients & 14 & 44 & 19 & 3 \\
\hline No intervention & $12(86)$ & $26 \quad(59)$ & $0 \quad(0)$ & $0 \quad(0)$ \\
\hline Interventiont & (14) & $18(41)$ & $19(100)$ & $3(100)$ \\
\hline Hydration & $(0)$ & $5(11)$ & $9(47)$ & $3(100)$ \\
\hline Administration of electrolytic supplement & $(14)$ & 3 (7) & $5(26)$ & $0 \quad(0)$ \\
\hline Chemotherapy stopped or changed & $(0)$ & 7 (16) & $13(68)$ & $3(100)$ \\
\hline Reduction in dose of cisplatin & (0) & $6(14)$ & $1 \quad(5)$ & $0 \quad(0)$ \\
\hline Delay of treatment & (7) & $4 \quad(9)$ & $2(11)$ & 1 (33) \\
\hline $\begin{array}{l}\text { Medication stopped (ACE inhibitor, ARB, } \\
\text { or NSAID) }\end{array}$ & (0) & (9) & 3 (16) & 1 (33) \\
\hline $\begin{array}{l}\text { Mean increase in serum creatinine }(\mu \mathrm{mol} / \mathrm{L}) \\
\text { Return to initial creatinine levelf }\end{array}$ & Grades & ombined & \multicolumn{2}{|c|}{$\begin{array}{r}\text { Grades } 2 \text { and } 3 \text { co } \\
75 \\
10(45) \neq\end{array}$} \\
\hline
\end{tabular}

$\overline{\mathrm{ACE}}=$ angiotensin-converting enzyme, $\mathrm{ARB}=$ angiotensin II receptor blocker, NSAID = nonsteroidal anti-inflammatory drug.

*Except where indicated otherwise.

tEach patient could have undergone more than one intervention.

¥No patients with a grade 3 increase in serum creatinine had creatinine return to initial level.

\section{Table 3. Potential Risk Factors for Nephrotoxicity}

Grade 2 or 3 versus Grade 0 or $1 *$

\begin{tabular}{|c|c|c|c|c|}
\hline \multirow{3}{*}{ Variable } & \multirow{2}{*}{\multicolumn{2}{|c|}{ Univariate Analysis }} & \multirow{2}{*}{\multicolumn{2}{|c|}{ Multivariate Analysis† }} \\
\hline & & & & \\
\hline & OR $(95 \% \mathrm{Cl})$ & $p$ Value & OR $(95 \% \mathrm{Cl})$ & $p$ Value \\
\hline Dose of cisplatin (mg) & $1.02(0.98$ to 1.06$)$ & 0.24 & $1.03(0.99$ to 1.08$)$ & 0.17 \\
\hline Age (years) & 0.99 (0.94 to 1.05$)$ & 0.86 & $0.97(0.91$ to 1.04$)$ & 0.45 \\
\hline \multicolumn{5}{|l|}{ Medications } \\
\hline Taking HCTZ (yes/no) & 9.35 (2.49 to 35.14$)$ & $<0.001$ & 5.39 (1.04 to 28.07$)$ & 0.045 \\
\hline Taking ACE inhibitor or ARB (yes/no) & $5.02(1.76$ to 14.32$)$ & 0.003 & $4.62(0.45$ to 47.18$)$ & 0.20 \\
\hline Taking NSAID (yes/no) & $1.60(0.47$ to 5.45$)$ & 0.45 & $1.90(0.41$ to 8.82$)$ & 0.41 \\
\hline \multicolumn{5}{|l|}{ Related medical condition $\neq$} \\
\hline$\geq 1$ versus none & $2.83(1.00$ to 7.98$)$ & 0.049 & $0.77(0.07$ to 8.24$)$ & 0.83 \\
\hline \multicolumn{5}{|c|}{$\begin{array}{l}\text { ACE = angiotensin-converting enzyme, ARB = angiotensin II receptor blocker, } \mathrm{Cl}=\text { confidence } \\
\text { interval, HCTZ = hydrochlorothiazide, NSAID = nonsteroidal anti-inflammatory drug, } \\
\text { OR = odds ratio. } \\
\text { * Grades refer to increase in serum creatinine. } \\
\text { †Adjusted for the following confounding variables: initial dose of cisplatin, age, concomitant } \\
\text { medication, and related medical condition. } \\
\text { fMedical conditions possibly associated with an increased risk of nephrotoxicity included } \\
\text { hypertension, diarrhea, limited fluid intake, past exposure to cisplatin, arteriosclerotic heart disease, myocardial infarc- } \\
\text { tion, bypass, and type } 2 \text { diabetes mellitus. }\end{array}$} \\
\hline
\end{tabular}

Table 4. Variation in Serum Creatinine According to Potential Risk Factors for Nephrotoxicity, by Linear Regression

\begin{tabular}{|c|c|c|c|}
\hline Variable & \multicolumn{2}{|c|}{$\begin{array}{l}\text { Increase in Serum Creatinine* } \\
(\mu \mathrm{mol} / \mathrm{L})(95 \% \mathrm{Cl})\end{array}$} & \multirow{2}{*}{$\begin{array}{c}\boldsymbol{p} \text { Value } \\
0.40\end{array}$} \\
\hline Dose of cisplatin (mg) & 0.2 & $(-0.3$ to 0.8$)$ & \\
\hline Age (years) & 1.1 & $(0.1$ to 2.1$)$ & 0.032 \\
\hline \multicolumn{4}{|l|}{ Medications } \\
\hline Taking HCTZ (yes/no) & 59.9 & (34.3 to 85.4$)$ & $<0.001$ \\
\hline Taking ACE inhibitor or ARB (yes/no) & 12.1 & $(-15.0$ to 39.2$)$ & 0.38 \\
\hline Taking NSAID (yes/no) & 21.4 & $(0.2$ to 42.7$)$ & 0.048 \\
\hline \multicolumn{4}{|l|}{ Related medical condition $\dagger$} \\
\hline None versus $\geq 1$ & -0.3 & $(-25.9$ to 25.2$)$ & 0.98 \\
\hline \multicolumn{4}{|c|}{$\begin{array}{l}\text { ACE = angiotensin-converting enzyme, ARB = angiotensin II receptor blocker, } \mathrm{Cl}=\text { confidence } \\
\text { interval, HCTZ = hydrochlorothiazide, NSAID = nonsteroidal anti-inflammatory drug. } \\
\text { *Adjusted for the following confounding variables: initial dose of cisplatin, age, concomitant } \\
\text { medication, and related medical condition. } \\
\text { †Medical conditions possibly associated with an increased risk of nephrotoxicity included } \\
\text { hypertension, diarrhea, limited liquid intake, past exposure to cisplatin, arteriosclerotic heart } \\
\text { disease, myocardial infarction, bypass, and type } 2 \text { diabetes mellitus. }\end{array}$} \\
\hline
\end{tabular}




\section{DISCUSSION}

In this retrospective cohort study, one-quarter of patients who received cisplatin experienced a grade 2 or 3 increase in serum creatinine on day 7. An intervention was performed for all of these patients. The logistic regression model showed that taking hydrochlorothiazide, but not an ACE inhibitor, ARB, or NSAID, was associated with a statistically significant increase in serum creatinine on day 7. The linear regression model showed that the average incremental increase in serum creatinine was $59.9 \mu \mathrm{mol} / \mathrm{L}$ among patients taking hydrochlorothiazide.

These findings correspond to those of several other studies; however, given that the definitions of nephrotoxicity differ greatly among studies, the results are difficult to compare. Shord and others ${ }^{3}$ defined nephrotoxicity as an increase in creatinine of $0.5 \mathrm{mg} / \mathrm{dL}(44 \mu \mathrm{mol} / \mathrm{L})$ and observed nephrotoxicity in $37 \%$ of cases following a cycle of treatment for head and neck cancer in a group of mostly African American patients. Máthé and others ${ }^{12}$ observed nephrotoxicity in $29 \%$ of patients following 1 to 4 cycles of cisplatin, where nephrotoxicity was defined as a decrease of at least $25 \%$ in creatinine clearance. In a study conducted in Japan, Yoshida and others ${ }^{13}$ observed a creatinine increase of grade 2 or higher in $30 \%$ of patients (NCI-CTCAE scale, version 4.0$)^{14}$ following 1 to 4 cycles of cisplatin. Lagrange and others ${ }^{15}$ reported that $15 \%$ of 121 cycles resulted in an increase in creatinine of $30 \%$ or more, with patients being followed for 1 to 6 cycles. In a study conducted in Korea, Moon and others ${ }^{16}$ investigated the $7 \%$ of patients $(n=41 / 552)$ who suffered post-cisplatin acute renal failure, defined by a creatinine value greater than $1.5 \mathrm{mg} / \mathrm{dL}$ $(132 \mu \mathrm{mol} / \mathrm{L})$. Mizuno and others ${ }^{17}$ studied 1721 Japanese patients who were treated mainly for esophagus, stomach, cervical, or lung cancer and found that $7 \%$ of patients experienced a grade 2 increase in creatinine on the NCI-CTCAE scale, version 4.03. ${ }^{11}$ In the study by Lavolé and others, ${ }^{18} 6 \%$ of patients with lung cancer had a grade 1 or higher increase in creatinine, based on the same scale as used in the current study. ${ }^{11}$ It should be emphasized that Lavolé and others ${ }^{18}$ measured creatinine weekly for all chemotherapy cycles and that the nadir value was retained in the analysis to evaluate nephrotoxicity. This could explain the low proportion of nephrotoxicity cases, relative to the current study.

Regarding grade 1 increases in creatinine, the proportion of cases varies considerably from one study to another: $41 \%$ for Máthé and others, ${ }^{12} 6 \%$ for Lavolé and others, ${ }^{18}$ and $55 \%$ in the current study. A grade 1 increase in creatinine was not considered clinically significant in the current study. This grade refers to increases no more than 1.5 times the upper limit of normal or baseline value. A slightly higher level of creatinine could be attributed to several confounding factors, such as measurement reliability and patients' hydration, exercise level, or catabolism. It is difficult to explain the differences in relation to studies by Moon and others ${ }^{16}$ and Mizuno and others, ${ }^{17}$ in which the reported rates were much lower. Several factors could affect these results: differences in study populations, comorbidities, types of cancers, types of protocols, and the moment when serum creatinine was analyzed.

All patients who experienced a grade 2 or 3 increase in creatinine underwent at least one intervention. Some of those who experienced a grade 1 increase also underwent interventions, but the proportion with a reduction in cisplatin dose was greater and the proportions who underwent forced hydration or a change in treatment were smaller, relative to patients with a grade 2 or 3 increase.

Patients taking hydrochlorothiazide were more likely to experience an increase in serum creatinine. However, the sample size in this study was too small to differentiate the impact of specific doses of this drug. The impact of other drug classes on renal function remains uncertain in the current study. Taking an ACE inhibitor or an ARB was associated with a greater risk of cisplatin-induced nephrotoxicity, according to analyses of different proportions, but was nonsignificant in the multivariate analyses (linear and logistic regression). This result may be explained by the possibility that patients took an ACE inhibitor or ARB combined with hydrochlorothiazide (as hydrochlorothiazide may be a confounding variable), or the number of patients may have been insufficient to detect a difference in this study. Shord and others ${ }^{3}$ found that hydrochlorothiazide and multivitamins were associated with more cases of nephrotoxicity following a cycle of cisplatin, whereas dexamethasone and ondansetron were inversely related. Lavolé and others ${ }^{18}$ also found a link between diuretics and ACE inhibitors and nephrotoxicity. In the current study, taking NSAIDs was associated with an increase in serum creatinine, but only according to the linear regression analysis. Whether patients took NSAIDs regularly or occasionally was not documented, which may have diluted the impact of taking them and may explain the differing results. Yoshida and others ${ }^{13}$ found an association between concomitant NSAID therapy and cisplatin-induced nephrotoxicity.

The impact of comorbidities was also analyzed in this study. Patients with at least one related medical condition were at greater risk of nephrotoxicity than those without any such conditions, according to analyses of different proportions, but this was nonsignificant in multivariate analyses (linear and logistic regression), when several confounding variables were taken into consideration. Medical conditions involving several health problems may have diluted the effect of each one. Several studies have found an association between certain comorbidities and nephrotoxicity. Máthé and others ${ }^{12}$ observed more severe nephrotoxicity in patients with hypertension associated with ischemic heart disease $(20.9 \%)$ and those with diabetes mellitus associated with ischemic heart disease (30.8\%), relative to patients without these comorbidities (7.5\%). Mizuno and others ${ }^{17}$ also observed an association between diabetes, heart disease, and stage 4 cancer and severe nephrotoxicity (defined as twice the baseline value). 
Lavolé and others ${ }^{18}$ also identified comorbidities (hypertension, diabetes, and heart disease) in patients with lung cancer as a risk factor for cisplatin-induced nephrotoxicity. However, Stewart and others ${ }^{19}$ found no association between acute cisplatin-induced nephrotoxicity and hypertension, atherosclerotic disease, or diabetes in a sample of 425 patients. Lavolé and others ${ }^{18}$ found no association between age, sex, cancer stage, and nephrotoxicity. In the current study, sex was not associated with greater nephrotoxicity. Linear regression analysis demonstrated that creatinine levels increased with age (by $1.12 \mu \mathrm{mol} / \mathrm{L}$ per year). There were only 5 patients $(6 \%)$ in whom a contrast agent was used a few days after chemotherapy, and use of such agents does not seem to have influenced the results. In short, comorbidities and patient characteristics associated with nephrotoxicity have not been concordant among the various studies performed to date.

This study had many strengths. First, increases in creatinine were graded according to the NCI-CTCAE standardized scale, which will ensure the study's reproducibility. Despite the existence of multiple versions, this scale remains the most widely used method of grading nephrotoxicity and the least at risk of interpretation, which reduces the potential risk of bias in the evaluation of nephrotoxicity. Serum creatinine data were available for all patients on day 7 , which allowed evaluation of the impact at a precise moment. Also, we were able to document all of the medications that patients were taking, because the pharmacist produced the medication history for each patient. Although the study was retrospective, several analyses adjusting for confounding variables were conducted.

Some limitations were also identified. The number of patients was perhaps insufficient to verify the impact of cisplatinbased chemotherapy on nephrotoxicity. Combining grades 0 and 1 and grades 2 and 3 for purposes of the analysis could be questioned. This action was deemed safe, reasonable, and clinically applicable, and it was suitable for determining whether or not patients required a major intervention. Measuring diuresis on the day of treatment and $72 \mathrm{~h}$ after treatment would have helped to ensure that patients were optimally hydrated. Given the retrospective design, it is possible that we were missing certain information for some patients (such as occurrence of nausea, vomiting, diarrhea, or change in medication during the week of treatment) if it was not documented in the medical file.

The long-term effects of cisplatin on renal function are not fully understood, but the potentially permanent glomerular filtration problems remain a concern, especially when the purpose of treatment is curative (meaning that patients may suffer from the damage for the rest of their lives) or when such problems prevent patients from receiving subsequent treatments. Therefore, further research is needed to understand the mechanism of cisplatin-induced nephrotoxicity and to determine how it can be prevented, to avoid irreversible damage and to ensure that renal function remains as efficient as possible. In light of the results of this study, patients should stop taking hydrochlorothiazide before undergoing cisplatin-based chemotherapy. Moreover, the definition of nephrotoxicity should be standardized to allow comparisons of results across different studies.

\section{CONCLUSION}

One-quarter of patients who received cisplatin experienced a grade 2 or 3 increase in serum creatinine on day 7 . Each of these affected patients underwent an intervention as a result. Taking hydrochlorothiazide was associated with a significant increase in serum creatinine on day 7. To avoid cisplatin-induced nephrotoxicity, identifying and warning those who are at risk remain essential. According to the results obtained, discontinuation of hydrochlorothiazide should be considered for patients who are receiving cisplatin-based chemotherapy, taking into account their individual medical condition. Patients who need hydrochlorothiazide therapy should be closely monitored for increase in serum creatinine. While their effects were nonsignificant, the use of ACE inhibitors, ARBs, and NSAIDs should probably also be questioned. A randomized clinical trial with comparative groups taking hydrochlorothiazide, ACE inhibitors, ARBs, and NSAIDs, with discontinuation of these medications before administration of the first cycle of cisplatin-based chemotherapy, could confirm the results obtained here concerning the frequency of cisplatininduced nephrotoxicity.

\section{References}

1. Pabla N, Dong Z. Cisplatin nephrotoxicity: mechanisms and renoprotective strategies. Kidney Int. 2008;73(9):994-1007.

2. dos Santos NA, Carvalho Rodrigues MA, Martins NM, dos Santos AC. Cisplatin-induced nephrotoxicity and targets of nephroprotection: an update. Arch Toxicol. 2012;86(8):1233-50.

3. Shord SS, Thompson DM, Krempl GA, Hanigan MH. Effect of concurrent medications on cisplatin-induced nephrotoxicity in patients with head and neck cancer. Anticancer Drugs. 2006;17(2):207-15.

4. Miller RP, Tadagavadi RK, Ramesh G, Reeves WB. Mechanisms of cisplatin nephrotoxicity. Toxins (Basel). 2010;2(11):2490-518.

5. Launay-Vacher V, Rey JB, Isnard-Bagnis C, Deray G, Daouphars M; European Society of Clinical Pharmacy Special Interest Group on Cancer Care. Prevention of cisplatin nephrotoxicity: state of the art and recommendations from the European Society of Clinical Pharmacy Special Interest Group on Cancer Care. Cancer Chemother Pharmacol. 2008;61(6):903-9.

6. Kintzel PE. Anticancer drug-induced kidney disorders. Drug Saf. 2001; 24(1):19-38.

7. Smit EF, van Meerbeeck JP, Lianes P, Debruyne C, Legrand C, Schramel F, et al. Three-arm randomized study of two cisplatin-based regimens and paclitaxel plus gemcitabine in advanced non-small-cell lung cancer: a phase III trial of the European Organization for Research and Treatment of Cancer Lung Cancer Group-EORTC 08975. J Clin Oncol. 2003;21(21):3909-17.

8. Winton T, Livingston R, Johnson D, Rigas J, Johnston M, Butts C, et al.; National Cancer Institute of Canada Clinical Trials Group; National Cancer Institute of the United States Intergroup JBR.10 Trial Investigators. Vinorelbine plus cisplatin vs. observation in resected non-small-cell lung cancer. $N$ Engl JMed. 2005;352(25):2589-97.

9. Curran WJ Jr, Paulus R, Langer CJ, Komaki R, Lee JS, Hauser S, et al. Sequential vs. concurrent chemoradiation for stage III non-small cell lung cancer: randomized phase III trial RTOG 9410. J Natl Cancer Inst. 2011;103(19):1452-60. Erratum in: J Natl Cancer Inst. 2012;104(1):79. 
10. Webb A, Cunningham D, Scarffe JH, Harper P, Norman A, Joffe JK, et al. Randomized trial comparing epirubicin, cisplatin, and fluorouracil versus fluorouracil, doxorubicin, and methotrexate in advanced esophagogastric cancer. J Clin Oncol. 1997;15(1):261-7.

11. Common Terminology Criteria for Adverse Events (CTCAE). Version 4.03. Bethesda (MD): National Institutes of Health, National Cancer Institute; 2010.

12. Máthé C, Bohács A, Duffek L, Lukácsovits J, Komlosi ZI, Szondy K, et al. Cisplatin nephrotoxicity aggravated by cardiovascular disease and diabetes in lung cancer patients. Eur Respir J. 2011;37(4):888-94.

13. Yoshida T, Niho S, Toda M, Goto K, Yoh K, Umemura S, et al. Protective effect of magnesium preloading on cisplatin-induced nephrotoxicity: a retrospective study. Jpn J Clin Oncol. 2014;44(4):346-54.

14. Common Terminology Criteria for Adverse Events (CTCAE). Version 4.0. Bethesda (MD): National Institutes of Health, National Cancer Institute; 2009.

15. Lagrange JL, Médecin B, Etienne MC, Pivot X, Cassuto-Viguier E, Renée $\mathrm{N}$, et al. Cisplatin nephrotoxicity: a multivariate analysis of potential predisposing factors. Pharmacotherapy. 1997;17(6):1246-53.

16. Moon HH, Seo KW, Yoon KY, Shin YM, Choi KH, Lee SH. Prediction of nephrotoxicity induced by cisplatin combination chemotherapy in gastric cancer patients. World J Gastroenterol. 2011;17(30):3510-7.

17. Mizuno T, Ishikawa K, Sato W, Koike T, Kushida M, Miyagawa Y, et al. The risk factors of severe acute kidney injury induced by cisplatin. Oncology. 2013;85(6):364-9.

18. Lavolé A, Danel S, Baudrin L, Gounant V, Ruppert AM, Epaud C, et al. Routine administration of a single dose of cisplatin $\geq 75 \mathrm{mg} / \mathrm{m}^{2}$ after short hydration in an outpatient lung-cancer clinic. Bull Cancer. 2012;99(4):E43-8.

19. Stewart DJ, Dulberg CS, Mikhael NZ, Redmond MD, Montpetit VA, Goel R. Association of cisplatin nephrotoxicity with patient characteristics and cisplatin administration methods. Cancer Chemother Pharmacol. 1997; 40(4):293-308.
Karine Almanric, BPharm, MSc, BCOP, is a Pharmacist with the Hôpital de la Cité-de-la-Santé (CISSS de Laval), Laval, Quebec.

Nathalie Marceau, BPharm, MSc, is a Pharmacist with the Hôpital de la Cité-de-la-Santé (CISSS de Laval), Laval, Quebec.

Ariane Cantin, PharmD, MSc, was, at the time of this study, a Pharmacy Resident at the Hôpital de la Cité-de-la-Santé (CISSS de Laval), Laval, Quebec.

Émilie Bertin, BPharm, MSc, is a Pharmacist with the Hôpital de la Citéde-la-Santé (CISSS de Laval), Laval, Quebec.

Competing interests: None declared.

\section{Address correspondence to:}

Nathalie Marceau

Hôpital de la Cité-de-la-Santé (CISSS de Laval)

1755, boulevard René Laennec

Laval QC H7M 3L9

e-mail: nmarceau2.csss|@ssss.gouv.qc.ca

Funding: This study was funded by the Oncology Research Group, Centre intégré de santé et services sociaux de Laval.

Acknowledgments: The authors would like to thank Djamal Berbiche, $\mathrm{PhD}$, for his time and effort in conducting the analysis and Lyne Lalonde, BPharm, PhD, without whom this project would not have been possible.

\section{ON THE FRONT COVER}

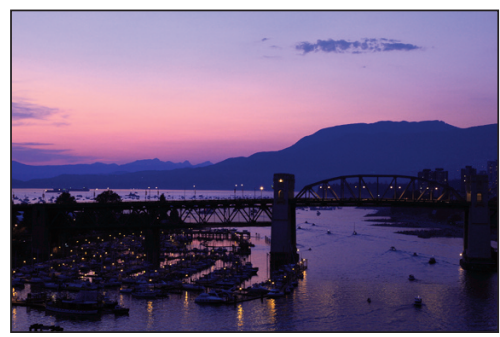

From One

Bridge to

Another

Vancouver,

British

\section{Columbia}

This photograph of the Burrard Street Bridge in Vancouver was shot, using a Canon 5D Mark II, from the vantage of the
Granville Street Bridge, while CSHP member Elaine Chong was waiting for the annual summer fireworks display to begin. Elaine is a Director with the Ministry of Health, Government of British Columbia.

The CJHP would be pleased to consider photographs featuring Canadian scenery taken by CSHP members for use on the front cover of the Journal. If you would like to submit a photograph, please send an electronic copy (minimum resolution $300 \mathrm{dpi}$ ) to publications@cshp.ca. 